\title{
Statistical Analysis of Oxidative Coupling of Methane in Membrane Reactors
}

\author{
M. Kalyani ${ }^{1}$, P. Chinmayi ${ }^{2}$, P. Meena ${ }^{3}$ \\ Department of Chemical Engineering \\ Chaitanya Bharathi Institute of Technology \\ Hyderabad, India
}

\begin{abstract}
Petroleum reserves are dwindling day by day, making the conversion of natural gas into other chemicals and fuels the major step in maintaining the fuel supplies and furthermore in contributing for the sustainable economic growth. Many a processes can be employed to achieve it but, compared to all the energy-intensive syn-gas formation techniques, the direct route that converts methane into higher hydrocarbons in one step employing oxidative coupling of methane is intensively studied here. This paper entirely focuses on reviewing the OCM technology in membrane reactor using the parametrical analysis procedure. In regards to which, parameters employed in the process such as temperature, feed ratio for different catalyst combinations are taken into consideration, owing to which the yield obtained and corresponding methane conversions are studied. The amount of impact these parameters have on the OCM process in the membrane reactor is analyzed by determining the effect percentages of the parameters individually using statistical analysis technique. The results make way for the formation of a hierarchical order of parameters, which gives a clarified view over the technique for the further developments to take place.
\end{abstract}

Keywords - OCM; Membrane reactor; statistical analysis; conversion; selectivity.

\section{INTRODUCTION}

Oxidative coupling of methane is a novel technology which has been followed since 1980's and was initially proposed by Keller and Bhasin (1982) [1-3] as a direct conversion process for the enhancement of ethane and ethylene as the desired products by the employment of methane as the major raw material. The process includes formation of hydrocarbons through coupling is known as coupling reaction which predominantly occurs in the presence of any oxidizing agent.OCM is possible only at higher temperatures and require proper care while processing of reactants. The major reactant, methane is activated on a heterogeneous catalyst surface at very high temperatures around 700-900, so as to evolve methyl free radicals, which are formed owing to the presence of oxygen available in the reactor either by direct injection or through the oxidative catalyst chosen. The methyl radicals obtained are coupled with one another to form $\mathrm{C}_{2}$ hydrocarbons and these radicals may also react with the available oxygen and form undesired complete oxidation products like $\mathrm{CO}_{\mathrm{x}}$. Apart from the desired $\mathrm{C}_{2} \mathrm{H}_{4}$ yields, the process also yields $\mathrm{C}_{2} \mathrm{H}_{6}$ at considerable levels owing to the subsequent dehydrogenation, and other higher hydrocarbons (e.g., $\mathrm{C}_{3} \mathrm{H}_{6}, \mathrm{C}_{3} \mathrm{H}_{8}$ ) at low levels [4]. The overall reaction is given below as follows:

$$
\begin{aligned}
2 \mathrm{CH}_{4}+\mathrm{O}_{2} & \rightarrow \mathrm{C}_{2} \mathrm{H}_{4}+2 \mathrm{H}_{2} \mathrm{O} \\
\Delta \mathrm{H}^{\circ}{ }_{298} & \approx-281 \mathrm{~kJ}
\end{aligned}
$$

A great deal of effort has recently been put on emphasizing the usage of conventional reactors. However, the limit of the yield of $\mathrm{C}_{2}$ products obtained in these reactors is about $25 \%$. The lower yields are seen because of the complete oxidation reactions occurring in the gas phase and partially on the catalyst surface under the conditions of high temperature and pressure [5]. Also, methyl radicals in the presence of high availability of oxygen may lead some amount of partial or complete oxidation products as the undesired by-products which decrease the desired product yield [6]. Membrane reactors are so used to control oxygen concentration offering possibility to achieve higher $\mathrm{C}_{2}$ hydrocarbon yield and selectivity. Among all the reactors these are safer for operation and are capable of separating oxygen from air simultaneously in one device [7].The membrane is typically made of oxygen ionic conducting ceramic material, containing a dense oxide membrane layer or sometimes porous membranes are used. The membrane layer is exposed to methane on one side and oxygen from the other side. The oxygen permeation through membrane can be controlled based on concentration requirement of oxygen in the reactor. The catalyst is in the form of coat at the surface of membrane exposed to methane. Both get reacted at the catalyst surface facilitating high $\mathrm{C}_{2}$ yield and selectivity due to limited oxygen concentration. The undesired products formed are separated easily in this reactor. [8]. At a certain fixed temperature and pressure the porous membrane reactor is capable of achieving about $30 \%$ yield with $53 \%$ selectivity of $\mathrm{C} 2$ products, whereas the fixed bed reactors and others provide a maximum yield of $20.7 \%$ at $52.5 \%$ selectivity. [7]Several parameters such as temperature, catalyst and the ratio of methane to oxygen have a large scope of effect on the yield and selectivity of $\mathrm{C}_{2}$ products. Therefore, parametric analysis in such a case is chosen to examine the effects of these parameters on the performance of OCM in membrane reactor

\section{LITERATURE COMPILATION}

Many researchers work was mostly emphasized on analyzing the effect of catalysts on the process in the membrane reactor. Under this, Y.Zeng in 1998 [10] conducted the experimentation using LSCFO (mixed conducting ceramic membrane material) with higher oxygen permeability as membrane with one surface exposed to $\mathrm{O}_{2} / \mathrm{N}_{2}$ mixture stream while the other is exposed to $\mathrm{CH}_{4} / \mathrm{He}$ mixture stream stating $\mathrm{C}_{2}$ yield increases with increase in the temperature. As far as concerned with the $\mathrm{C}_{2}$ selectivity-it 
increases with increase in temperature from $800-850^{\circ} \mathrm{C}$ and decreases with increase in temperature from $850-950^{\circ} \mathrm{C}$ respectively and also proved that the high rate of increase in the yield and selectivity of $\mathrm{C}_{2}$ hydrocarbons is due to the fact that the membrane is more permeable to the oxygen. The yield and selectivity's obtained here are $2.5 \%-17.3 \%$ and $41 \%-87 \%$ and the methane conversion ranges from $5.2 \%$ $1.1 \%$ at $900^{\circ} \mathrm{C}$ which is not possible with most of the catalysts used in the conventional type of reactors [10]. Later, Xiaoyao Tan (2007) conducted his research completely emphasizing on the change in temperatures and the reactor performance with and without a STL catalyst [11]. His research proved that at higher temperatures, methane conversion is gradually high when compared to low temperature activities. The $\mathrm{C}_{2}$ selectivity achieved gradually decreases with increase in temperature from 1100 to $1200 \mathrm{~K}$ and it increases with increase in temperature from 998 to $1100 \mathrm{~K}$ similar to the yields obtained. The maximum yield he achieved was about $11.9 \%$ with $42.7 \%$ of $\mathrm{C}_{2}$ selectivity at $1098 \mathrm{~K}$ [11]. Olivier in 2009 started studying the OCM process with other membrane compositions and catalysts. His experiments were conducted without and with different catalysts in a BSCFO membrane reactor such that the concentration of methane entering the reactor is fixed to $10 \%$ [12]. The conversion and yield of the desired compounds tended to remain below $10 \%$ without the catalyst, whereas the conversions of $\mathrm{La}-\mathrm{Sr} / \mathrm{CaO}$ and $\mathrm{Sr} / \mathrm{La}_{2} \mathrm{O}_{3}$ reached $30 \%$ and $25 \%$ [12]. His conclusions also stated that the selectivity of $\mathrm{C}_{2}$ hydrocarbons exceeds $60 \%$ and $40 \%$ for the reactors with La$\mathrm{Sr} / \mathrm{CaO}$ and $\mathrm{Sr} / \mathrm{La}_{2} \mathrm{O}_{3}$ catalysts. The most attracting feature of his research work was that the catalysts employed gave higher selectivity at lower temperatures which is quite hard to achieve. From further evaluation, he also concluded that the selectivity of $\mathrm{Sr} / \mathrm{La}_{2} \mathrm{O}_{3}$ has no significance as it is much less compared to the bare membrane used at $800^{\circ} \mathrm{C}(1073 \mathrm{~K})$, whereas $\mathrm{LaSr} / \mathrm{CaO}$ allows a selectivity of about $40 \%$ at the same temperature under considerable conditions. His conclusions were highly rated as they gave a complete guide for the choice of the best catalyst [12]. But apart from the other researchers Patcharavorachot around in 2014 took a different approach by considering a mathematical model of the OCM process coupled with the kinetic model to examine the performance of OCM in membrane reactor in terms of $\mathrm{CH}_{4}$ conversion, $\mathrm{C}_{2}$ selectivity and $\mathrm{C}_{2}$ yield [13]. $\mathrm{He}$ conducted a simulation study using OCM membrane reactor operated at higher temperatures and lower feed ratios $\left(\mathrm{CH}_{4} / \mathrm{O}_{2}\right)$ can improve $\mathrm{C}_{2}$ production. Here simulation results are compared with the experimental values chosen from the Stansch et al, 1997 [1]. The values from their research works are compiled into analysis tables as depicted in Table I - V.

\section{RESEARCH METHODOLOGY}

Statistical analysis, in other words can be termed as the quantitative analysis for a process under consideration. And by implementing the statistical analysis on the go both the major targets i.e. the quantitative analysis and the effect percentages of the parameters can be obtained at the same time [10].Under this, the experimental values of the process are required. These values include the conversion percentages, the selectivity percentage of the products; simply put all the values that play a major role in understanding the performance of the reactor that is employed for the process, which are obtained at different parameter combinations. $2^{\mathrm{k}}$ factorial method is one among them which is chosen for carrying out of the research work. $2^{\mathrm{k}}$ factorial designs are used to determine the effect of ' $\mathrm{k}$ ' factors, each of which has 2 alternatives or levels. This approach helps in sorting out factors in the order of their impact, especially when the effect of parameters is quite large [9]. Considering a case, which employs 2 different parameters where each parameter has 2 alternatives i.e., peak positions of the parameter. To obtain the percentage effect of each parameter individually, the following formulae are employed:

If $y$ denotes the experimental value, the output can be modeled using non-linear regression model as:

Where,

$$
\mathrm{y}=\mathrm{q}_{0}+\left(\mathrm{q}_{\mathrm{A}} * \mathrm{x}_{\mathrm{A}}\right)+\left(\mathrm{q}_{\mathrm{B}} \mathrm{x}_{\mathrm{B}}\right)+\left(\mathrm{q}_{\mathrm{AB}} * \mathrm{x}_{\mathrm{A}} * \mathrm{x}_{\mathrm{B}}\right)
$$

$\mathrm{x}_{\mathrm{A}}, \mathrm{x}_{\mathrm{B}}$ are the variables that represent the factors like temperature and $\mathrm{CH}_{4} / \mathrm{O}_{2}$ ratio respectively, q's are the effects. The importance of a factor can be explained in detail by the proportion of total variation in the response of the factor. The variation of $y$ or the sum of squares total (SST) is given by

$$
\mathrm{SST}=\sum_{\mathrm{k}=0}^{4}(\mathrm{yi}-\mathrm{yijavg})^{\wedge} 2
$$

For a $2^{2}$ design, the variation can be divided into three parts:

$$
\mathrm{SST}=\mathrm{SSA}+\mathrm{SSB}+\mathrm{SSAB}
$$

Where,

SSA and SSB are the sum of squares for treatments A and B; SSAB is sum of squares of interaction and SST represent total sum of squares.

$$
\mathrm{SST}=2 * \mathrm{q}_{\mathrm{A}}{ }^{2}+2^{2 *} \mathrm{q}_{\mathrm{B}}{ }^{2}+2^{2 *} \mathrm{q}_{\mathrm{AB}}{ }^{2}
$$

Leading us with weightages of the effect each parameter has on OCM process.

TABLE I: Analysis table for membrane reactor at Normal varying temperatures

\begin{tabular}{|l|l|l|l|}
\hline Temperature $\left({ }^{\circ} \mathrm{C}\right)$ & \multicolumn{3}{|c|}{$\mathrm{C}_{2}$ Yield } \\
\hline Catalyst $\rightarrow$ & $\begin{array}{l}\mathrm{Li} / \mathrm{MgO} \\
\text { on } \\
\text { LSCFO }\end{array}$ & $\begin{array}{l}\mathrm{LaSr} / \mathrm{CaO} \text { on } \\
\mathrm{BSCFO}\end{array}$ & $\begin{array}{l}\mathrm{La}_{2} \mathrm{CO}_{3} \text { on } \\
\mathrm{BSCFO}\end{array}$ \\
\hline 800 & 7.2 & 14 & 22 \\
\hline 850 & 11.1 & 15 & 27 \\
\hline
\end{tabular}

TABLE II: Analysis table for membrane reactor under constant feed ratio

\begin{tabular}{|l|l|l|ll|}
\hline Temperature $\left({ }^{\circ} \mathrm{C}\right)$ & \multicolumn{4}{|c|}{$\mathrm{CH}_{4}$ Conversion } \\
\hline Catalyst $\rightarrow$ & $\begin{array}{l}\mathrm{Li} / \mathrm{MgO} \text { on } \\
\text { LSCFO }\end{array}$ & $\begin{array}{l}\mathrm{LaSr} / \mathrm{CaO} \text { on } \\
\mathrm{BSCFO}\end{array}$ & $\begin{array}{l}\mathrm{La}_{2} \mathrm{CO}_{3} \\
\mathrm{BSCFO}\end{array}$ \\
\hline 800 & 17.6 & 20 & 40 \\
\hline 850 & 19 & 25 & 50 \\
\hline
\end{tabular}

TABLE III: Analysis table of membrane reactor under varying feed ratios

\begin{tabular}{|l|l|l|}
\hline Feed Ratio & \multicolumn{2}{|c|}{$\mathrm{C}_{2}$ Yield } \\
\hline Catalyst $\rightarrow$ & $\mathrm{Li} / \mathrm{MgO}$ on $\mathrm{LSCFO}$ & $\mathrm{La}_{2} \mathrm{CO}_{3}$ on $\mathrm{BSCFO}$ \\
\hline 2 & 8.6 & 25 \\
\hline 4 & 12 & 30 \\
\hline
\end{tabular}

TABLE IV: Analysis table for membrane reactor using a single catalyst under varying temperature and feed ratio

\begin{tabular}{|l|c|c|}
\hline Temperature $\left({ }^{\circ} \mathrm{C}\right)$ & \multicolumn{2}{|c|}{$\mathrm{C}_{2}$ Yield } \\
\hline Feed Ratio $\rightarrow$ & $2.0 \mathrm{CH}_{4} / \mathrm{O}_{2}$ & $6.0 \mathrm{CH}_{4} / \mathrm{O}_{2}$ \\
\hline 850 & 7.2 & 8.6 \\
\hline 950 & 2.5 & 12 \\
\hline
\end{tabular}


TABLE V: Analysis table for membrane reactor at high temperatures

\begin{tabular}{|l|c|c|}
\hline Temperature $\left({ }^{\circ} \mathrm{C}\right)$ & \multicolumn{2}{|c|}{$\mathrm{C}_{2}$ Yield } \\
\hline Feed Ratio $\rightarrow$ & $2.0 \mathrm{CH}_{4} / \mathrm{O}_{2}$ & $6.0 \mathrm{CH}_{4} / \mathrm{O}_{2}$ \\
\hline 850 & 7.2 & 8.6 \\
\hline 950 & 2.5 & 12 \\
\hline
\end{tabular}

\section{STATISTICAL ANALYSIS CALCULATIONS}

Factorial design technique is now applied on the tables I - V to find the percentage weightage of the parameter impact on the OCM process. Table VI gives the information about the sample calculations for the $\mathrm{C}_{2}$ yield $(\mathrm{Y})$ analysis in the membrane reactor. Here, the catalyst is considered as the factor $\mathrm{A}$, temperature as factor $\mathrm{B}$ and $\mathrm{AB}$ id taken as the interaction effect. The data at various catalysts and at specified temperatures are indexed as ' $\mathrm{i}$ ' and ' $\mathrm{j}$ '.

SSA, the sum of the squares of error for parameter A (catalyst) is calculated using the product of two terms, i.e., the difference between average $\mathrm{C}_{2}$ yield $\left(\mathrm{Y}_{\mathrm{ijavg}}\right)$ and the average $\mathrm{C}_{2}$ yield for each catalyst individually ( $\mathrm{Y}_{\text {cavg }}$ ) and replicates the number of temperature points considered (in this case 2).

$\mathrm{SSB}$, the sum of squares of error for parameter B (temperature) is also calculated using two terms which in this case is the difference between the average $\mathrm{C}_{2}$ yield ( $\mathrm{Y}_{\mathrm{ijavg}}$ ) and the average $\mathrm{C}_{2}$ yield at specified temperatures separately $\left(\mathrm{Y}_{\text {tavg }}\right)$ and replicates the number of catalysts under consideration (in this case 3 ).

And finally, SST, the sum of squares of error for each yield data from the average $\mathrm{C}_{2}$ yield $\left(\mathrm{Y}_{\mathrm{iavg}}-\mathrm{Y}\right)$ is calculated. And SSAB is calculated using equation 3 and later using the percentage calculation technique the weightages are calculated as depicted in table VII. Similar Calculations are performed as explained in table VI for the other parameters taken into consideration as in Table I - V.

TABLE VI: Calculation table for table I

\begin{tabular}{|c|c|c|c|c|c|}
\hline Temperature $\left({ }^{\circ} \mathrm{C}\right)$ & \multicolumn{3}{|c|}{$\mathrm{C}_{2}$ Yield } & \multirow[b]{2}{*}{ Average $\left(\mathrm{Y}_{\text {tavg }}\right)$} & \multirow{2}{*}{$\begin{array}{l}\text { Square of error }\left(\mathrm{Y}_{\mathrm{ijavg}}-\right. \\
\left.\mathrm{Y}_{\text {tavg }}\right)^{2}\end{array}$} \\
\hline Catalyst $\rightarrow$ & $\mathrm{Li} / \mathrm{MgO}$ & $\begin{array}{ll}\mathrm{LaSr} / \mathrm{CaO} & \text { on } \\
\mathrm{BSCFO} & \end{array}$ & $\mathrm{La}_{2} \mathrm{CO}_{3}$ on $\mathrm{BSCFO}$ & & \\
\hline 800 & 7.2 & 14 & 22 & 14.4 & 2.722 \\
\hline 850 & 11.1 & 15 & 27 & 17.7 & 2.722 \\
\hline Average $\left(Y_{\text {cavg }}\right)$ & 9.15 & 14.5 & 24.5 & $16.05\left(\mathrm{Y}_{\mathrm{ijavg}}\right)$ & - \\
\hline $\begin{array}{l}\text { Square of error } \\
\left(Y_{\text {ijavg }}-Y_{\text {cavg }}\right)^{2}\end{array}$ & 47.61 & 2.4025 & 71.402 & $\begin{array}{l}\Sigma\left(Y_{\text {ijavg }}-Y_{\text {cavg }}\right)^{2} \\
121.4145\end{array}$ & $\Sigma\left(\mathrm{Y}_{\mathrm{ijavg}}-\mathrm{Y}_{\text {tavg }}\right)^{25.444}$ \\
\hline \multirow{2}{*}{$\begin{array}{l}\text { Square of each } \\
\text { error }\left(Y_{i j a v g}-Y_{I}\right)^{2}\end{array}$} & 78.322 & 4.2025 & 35.402 & - & - \\
\hline & 24.502 & 1.102 & 119.902 & - & - \\
\hline
\end{tabular}

TABLE VII: Effect percentage table for the calculation Table VI

\begin{tabular}{|c|c|c|}
\hline Parameter & Sum of squares of error & Effect percent \\
\hline A-CATALYST & 242.829 & $92.17 \%$ \\
\hline B-TEMPERATURE & 16.332 & $6.199 \%$ \\
\hline AB-INTERACTION & 4.271 & $1.621 \%$ \\
\hline TOTAL & 263.432 & $100 \%$ \\
\hline
\end{tabular}

TABLE VIII: Results showing the percentages of impact of each parameter

\begin{tabular}{|c|c|c|c|c|c|}
\hline \multirow{3}{*}{ FACTOR } & \multicolumn{5}{|c|}{ MEMBRANE REACTOR } \\
\hline & \multicolumn{3}{|c|}{$C_{2}$ YIELD } & \multicolumn{2}{|c|}{$\mathrm{CH}_{4} \mathrm{CONVERSION}$} \\
\hline & TABLE-I & TABLE-III & TABLE-IV & TABLE-II & TABLE-V \\
\hline$A$ & $\begin{array}{c}\text { CATALYST } \\
92.2 \%\end{array}$ & $\begin{array}{c}\text { CATALYST } \\
94 \%\end{array}$ & $\begin{array}{c}\text { FEED RATIO } \\
63.8 \%\end{array}$ & $\begin{array}{c}\text { CATALYST } \\
92 \%\end{array}$ & $\begin{array}{c}\text { CATALYST } \\
79.4 \%\end{array}$ \\
\hline$B$ & $\begin{array}{l}\text { TEMP } \\
6.2 \% \\
\end{array}$ & $\begin{array}{c}\text { FEED RATIO } \\
5.6 \%\end{array}$ & $\begin{array}{c}\text { TEMP } \\
1 \%\end{array}$ & $\begin{array}{l}\text { TEMP } \\
5 \%\end{array}$ & $\begin{array}{l}\text { TEMP } \\
7.9 \%\end{array}$ \\
\hline$A B$ & $\begin{array}{c}\text { BOTH } \\
1.6 \% \\
\end{array}$ & $\begin{array}{l}\text { BOTH } \\
0.001 \%\end{array}$ & $\begin{array}{l}\text { BOTH } \\
35.2 \% \\
\end{array}$ & $\begin{array}{l}\text { BOTH } \\
2.7 \% \\
\end{array}$ & $\begin{array}{l}\text { BOTH } \\
12.5 \% \\
\end{array}$ \\
\hline
\end{tabular}




\section{RESULTS AND CONCLUSION}

Similar Calculations are performed as explained in table VI for all other parameters taken into consideration as in Table I$\mathrm{V}$. And the results obtained from the calculations done are compiled together in the form of a table. The results are shown as columns in the Table VII.

From table VIII quite a few concluding statements can be clearly made out. Starting with, though OCM process is usually seen as very high temperature dependent process the impact temperature has on the process is very much minimal in comparison to that of the catalyst. And, the $\mathrm{C}_{2}$ yield is predominantly depends upon the type of the catalyst employed in the process i.e., on the catalyst selection in the membrane reactors. Though quite a fuss is created around the impact of feed ratio $\left(\mathrm{CH}_{4} / \mathrm{O}_{2}\right)$ and its importance owing to which many researches are concentrating more on its effect, from the results obtained it can be noted that feed ratio is not a critical parameter when compared to the temperature changes and the choice of the catalyst. From the analysis of various parameters for the production of ethylene using OCM process, it can be concluded that the parameters for research should be in the priority order as Catalyst, Temperature and Feed ratio $\left(\mathrm{CH}_{4} / \mathrm{O}_{2}\right)$ for the production of $\mathrm{C}_{2}$ compounds. From this research it can be clearly be stated that the time and further efforts in the making developments must be more centered towards the catalyst than the other factors as even a minute developments in the catalyst used can turn this process into a trustworthy one for the future generations.

\section{REFERENCES}

[1] Keller GE, Bhasin MM, Synthesis of ethylene via oxidative coupling of methane, J Catal Today, 73:9-19, 1982

[2] Yaghobi N., Ghoreishy, M. H. R., Oxidative coupling of methane in a fixed bed reactor over perovskite catalyst: A simulation study using experimental kinetic model, Journal of Natural Gas Chemistry, 17(1), $8-16,2008$

[3] Haihui Wang, You Cong, Weishen Yang ,Oxidative coupling of methane in $\mathrm{Ba}_{0.5} \mathrm{Sr}_{0.5} \mathrm{Co}_{0.8} \mathrm{Fe}_{0.2} \mathrm{O}_{3 \mathrm{~d}}$ tubular membrane reactors, Catalysis Today, 104, 160-164, 2005.

[4] Z. Stansch, L. Mleczko, and M. Baerns, Comprehensive kinetics of oxidative coupling of methane over the $\mathrm{La}_{2} \mathrm{O}_{3} / \mathrm{CaO}$ catalyst, Indust. Eng. Chem. Res. 36, 2568-2579, 1997.

[5] Kort, Catalysts for the oxidative coupling of methane, Ph.D. Thesis, University of Twenty, The Netherlands, 2009.

[6] Zavyalova U, Geske M, Horn R, Weinberg G,Frandsen W, Schuster M, et al., Morphology and microstructure of $\mathrm{Li} / \mathrm{MgO}$ catalysts for the oxidative coupling of methane, ChemCatchem;3:949-59, 2011

[7] W. Wang, Y.S. Lin, Analysis of oxidative coupling of methane in dense oxide membrane reactors, Journal of membrane science, 103, 219-233, 1995.

[8] Mohammad R. Quddus, Yan Zhang, and Ajay K. Ray, Multi-objective Optimization of a Porous Ceramic Membrane Reactor for Oxidative Coupling of Methane, Ind. Eng. Chem. Res. 2010, 49, 6469-6481, 2010.

[9] M. Kalyani, V Ramesh kumar, SuggalaSatyanarayana, Effect of various parameters on oxidative coupling of methane, Journal of Chemical Engineering and Research, volume-2, pg: 223-230, 2014.

[10] Y.Zeng, Y.S. Lina, S.L Swartz, Perovskite-type ceramic membrane synthesis, oxygen permeation and membrane reactor performance for oxidative coupling of methane, Journal of membrane science 150, 8798, 1998.

[11] Xiaoyao Tan, Zhaobao Pang, ZiGub, Shaomin Liu, Catalytic perovskite hollow fiber membrane reactors for methane oxidative coupling, Journal of Membrane Science 302, 109-114, 2007.

[12] Louis Olivier, Ste'phane Haag, Claude Mirodatos, Andre C. van Veen., Oxidative coupling of methane using catalyst modified dense perovskite membrane reactors, Catalysis Today 142, 34-41, 2009. 